\title{
Hacia un discurso sobre la ciudad en el Nuevo Mundo: el caso de Gonzalo Fernández de Oviedo
}

\section{Towards a Discourse about the City in the New World: the Example of Gonzalo Fernández de Oviedo}

\section{Álvaro Baraibar}

Universidad de Navarra, GRISO

ESPAÑA

abaraibar@unav.es

[Hipogrifo, (issn: 2328-1308), 5.2, 2017, pp. 347-355]

Recibido: 12-09-2017 / Aceptado: 13-10-2017

DOI: http://dx.doi.org/10.13035/H.2017.05.02.20

Resumen. El presente trabajo es un primer acercamiento a la forma en la que Gonzalo Fernández de Oviedo construye, en sus obras americanas, un discurso específico a la hora de describir la ciudad americana. Concretamente, me ha interesado analizar las vías a través de las que el primer cronista de Indias adapta formas retóricas de largo recorrido en el viejo continente al presentar al lector esa nueva realidad que constituía la ciudad americana. El caso de Santo Domingo, ciudad a la que Gonzalo Fernández de Oviedo estuvo especialmente ligado, servirá de ejemplo para ver la manera en la que el cronista adapta la fórmula del panegírico de la ciudad al Nuevo Mundo.

Palabras clave. Crónicas de Indias; siglo XVI; Gonzalo Fernández de Oviedo; retórica; ciudad americana.

Abstract. This paper aims to be an initial approach to the way in which Gonzalo Fernández de Oviedo puts up an specific discourse in his work at the time of describing the American city. Concretely, I have been interested in analyzing the ways the first chronicler of the American Indies adapts long-time used formulas from the old continent when he is introducing the reader to the new reality constituted by the American city. That is the case of Santo Domingo, a city to which Gonzalo Fernán- 
dez de Oviedo was especially bounded. It will serve us as an example to study how the chronicler adapts the formula of the panegyric of the city to the New World.

Keywords. Spanish Chronicles of the Indies; 16th Century; Gonzalo Fernández de Oviedo; Rhetoric; American City.

\section{INTRODUCCIÓN}

El objetivo de este artículo no es otro que llevar a cabo un primer acercamiento al proceso de construcción de un discurso sobre la ciudad en las obras americanas de Gonzalo Fernández de Oviedo. El texto pretende analizar las estrategias discursivas de Oviedo al describir las características de la ciudad de nueva creación en las Indias Occidentales a mediados del siglo XVI y ver si la manera de referirse a ella toma los mismos patrones que se estaban dando en la literatura peninsular o cambia de forma sustancial, incorporando en la narración elementos propios del espacio de experiencia americano'. Me centraré para ello, en el caso de Santo Domingo, primer asentamiento español en América, y punto de partida en aquel momento de las misiones de descubrimiento y conquista. Además, Santo Domingo era una ciudad que Gonzalo Fernández de Oviedo conoció especialmente bien al vivir en ella durante muchos años.

\section{SANTO DOMINGO}

En las primeras referencias de Gonzalo Fernández de Oviedo a la fundación de asentamientos de españoles en Indias, la mirada del cronista no se detiene en ningún momento en describir dichas poblaciones. Su interés es meramente informativo. El discurso del cronista se centra en mostrar los avances del almirante en su descubrimiento de las islas en busca de oro. La fundación de ciudades y fortalezas es más una necesidad coyuntural en la búsqueda de las riquezas deseadas y en el proceso de descubrimiento e identificación de los territorios explorados que un motivo de interés o de preocupación para él. Así, la noticia de la primera edificación, el «castillo» donde Cristóbal Colón dejó a 38 de sus marineros, alude a que se hizo «con la madera de la carabela capitana o Gallega [...] e con fajina e tierra, lo mejor que se pudo fabricar»².

Sin embargo, la percepción de las construcciones en América cambia en Oviedo poco más adelante, en el contexto de la descripción de las maravillas de las Indias Occidentales. Ya en el capítulo 2 del Sumario (1526), Oviedo, al hablar sobre la Española, había descrito la belleza de la ciudad de Santo Domingo que, como ya

1. Ver al respecto Baraibar, 2011.

2. Fernández de Oviedo, Historia, vol. 1, p. 27. Cuando Oviedo explica cómo el almirante había fundado la ciudad de la Isabela y la fortaleza de Santo Tomás, lo hace tras referir la noticia de la muerte de los 38 cristianos y explica cómo la fortaleza se había erigido en las minas de Cibao, las más ricas de la isla, tan pronto como se había tenido noticia de ellas (Fernández de Oviedo, Historia, vol. 1, p. 47). 
he dicho, fue el primer asentamiento español en América y enclave estratégico en el proceso de descubrimiento y conquista. Santo Domingo era una ciudad, en opinión del cronista, a la que ninguna población de España, ni siquiera Barcelona, «le hace ventaja generalmente»:

y el asiento muy mejor que el de Barcelona, porque las calles son tanto y más llanas y muy más anchas y sin comparación más derechas, porque como se ha fundado en nuestros tiempos, demás de la oportunidad y aparejo de la disposición para su fundamento, fue trazada con regla y compás, y a una medida las calles todas, en lo cual tiene mucha ventaja a todas las poblaciones que he visto ${ }^{3}$.

Tal y como ha destacado Vanina María Teglia para el caso de Santa María del Darién - primer lugar de residencia de Gonzalo Fernández de Oviedo en América-, la descripción que el cronista hace de Santo Domingo también tiene los rasgos propios de un panegírico de la ciudad, un tipo de discurso frecuente en la época y que cuenta con su propia tradición 4 . Teglia, siguiendo en este caso el trabajo de Ernst Curtius, se refiere a los tres tópicos presentes en estos panegíricos de ciudades: elogio de la fertilidad del lugar, de las riquezas de las edificaciones y de los logros artísticos e históricos de la ciudad y de sus habitantes 5 . Oviedo, en el Sumario, sigue en lo fundamental dicho esquema y ensalza «la fertilidad y abundancia de la tierra», los edificios de piedra con «hermosas tapias» haciendo una «singular argamasa», el trazado de las calles, el puerto, la presencia de casas tan buenas «que cualquiera de los grandes de Castilla se podrían muy bien aposentar en ellas», la iglesia catedral y los conventos. Y la dignidad de la ciudad también se ve enriquecida por la presencia de «santos religiosos y de grande ejemplo», así como por el hecho de que hubiera en ella una residencia del virrey, una audiencia y una chancillería real, de modo que la ciudad se iría ennobleciendo cada vez más ${ }^{6}$. La autoridad de las instituciones presentes en la ciudad se transfiere a la ciudad misma incrementando la dignidad y nobleza de la misma?

Hasta aquí Gonzalo Fernández de Oviedo sigue básicamente las pautas generales marcadas en estos panegíricos de la ciudad de modo similar a lo que se hacía para cualquier ciudad del mundo ya conocido. Sin embargo, es el tercer tópico, el de «los logros artísticos e históricos de sus habitantes», utilizando las palabras de Teglia ${ }^{8}$, el que marca una clara diferencia y tendrá un matiz propio en el caso de las ciudades americanas.

3. Fernández de Oviedo, Sumario, p. 79.

4. Teglia, 2012, pp. 9-10. Ver, en este sentido, el proceso de creación de un discurso renacentista sobre una Sevilla ideal durante el siglo XVI, descrito por Lleó, 1979, esp. pp. 153-203.

5. Teglia, 2012, p. 10. Ver Curtius, 1955, pp. 224-231, esp. p. 228. Lleó, 1979, p. 154, destaca en el caso de Sevilla la presencia de algunos de estos tópicos ya en la literatura musulmana y se refiere a ellos como "elogios" de Sevilla», pero sin analizar esta cuestión desde la perspectiva de la retórica.

6. Fernández de Oviedo, Sumario, pp. 79-82. Sobre la ekfrasis y el discurso panegírico en Oviedo, ver Carrillo, 2004, pp. 205 y ss.

7. Sobre el concepto de autoridad en Gonzalo Fernández de Oviedo, ver Baraibar, 2014.

8. Teglia, 2012, p. 10 
Más allá de alabar la fertilidad del lugar y la idoneidad de las edificaciones, Oviedo, al referirse a Santo Domingo, se centra en elogiar la «modernidad» de la ciudad. Poco antes de que Oviedo escribiera el Sumario, en 1523, el emperador Carlos V había aprobado una ordenanza por medio de la cual se regulaba la forma en que debía diseñarse la planta de las nuevas poblaciones que se fundaran en el Nuevo Mundo. Así, la ordenanza explicaba cómo se debía repartir el espacio «por sus plazas, calles y solares a cordel y regla, comenzando desde la plaza mayor, y sacando desde ella las calles a las puertas y caminos principales»⿳9. Esta ordenanza desarrollaba, breve pero significativamente, textos anteriores que, en buena medida, se limitaban a aconsejar en todo caso que «el pueblo parezca ordenado», ya que «en los lugares que de nuevo se hacen, dando la orden en el comienzo, sin ningún trabajo ni costa quedan ordenados y los otros jamás se ordenan $»^{10}$. Es fácil pensar que Oviedo conoció la ordenanza de primera mano, ya que entre 1523 y 1526 estuvo en la corte de Carlos V ${ }^{11}$.

La condición de nueva fundación, erigida siguiendo las instrucciones del emperador Carlos $\vee$ a partir de las ideas que imperaban «en nuestros tiempos», era precisamente lo que hacía que para el cronista madrileño Santo Domingo aventajara a cualquier otra ciudad. En el marco del panegírico de la ciudad que desarrolla Oviedo poco importaba que Santo Domingo no fuera exactamente esa ciudad trazada a «regla y compás» ${ }^{12}$.

9. Recopilación de leyes de los reinos de las Indias, vol. II, p. 19. García Zarza, 1996, pp. 77-79, al referirse a las primeras ordenanzas que regulan la fundación de ciudades en América, se sorprende de que no hicieran mención a la ordenación urbanística hasta que Carlos V promulgara su texto. Por su parte, Francisco de Solano (1990; 1996), no tiene en cuenta la ordenanza de Carlos V al afirmar que no fue hasta 1573 cuando se reguló por primera vez aspectos urbanísticos en la fundación de ciudades en territorio americano (1990, p. 42). Ver también Solano, 1987. Brewer-Carías, 2006, p. 202, menciona la influencia de las nuevas pueblas aragonesas y castellanas y de los escritos de Eiximenis, Vitruvio y Alberti en estas ordenanzas. Ver, asimismo, Bielza de Ory, 2002.

10. «Instrucción al gobernador de Tierra Firme...» (1513), recogida por Solano, 1996, p. 37. Se trata de la instrucción de Fernando el Católico a Pedrarias Dávila. Por otro lado, la Ordenanza de Población (1573) de Felipe II incluyó como artículo 111 la de Carlos V, marcando una clara continuidad en las ideas urbanísticas en la fundación de nuevos asentamientos en América, si bien es cierto que los 112 y siguientes introdujeron mayores especificaciones sobre el trazado de la plaza y otros aspectos. Esto último lleva a Nicolini a afirmar que «el tipo cuadricular fue puesto en cuestión por la legislación promulgada por Felipe II en 1573» por las medidas definidas para la plaza, de forma rectangular (2005, p. 31). Para un análisis de ambas ordenanzas desde un punto de vista arquitectónico, ver Goyoaga, 1989.

11. Como se verá más adelante, resulta evidente que la conocía, al menos, cuando escribe sobre Santo Domingo en la Historia.

12. Hardoy, 1975, p. 337 se refiere a Santo Domingo como un asentamiento con «reminiscencias medievales tardías». Por contra, Brewer-Carías defiende que la ciudad tenía «una forma urbana bastante reticular» (2006, p. 285) como consecuencia del paso de Ovando por Santa Fe, fundada como un «rectángulo fortificado» en la vega de Granada en el final de la Reconquista (p. 287). Marías, 1986, p. 85, afirma que en el caso de las ciudades peninsulares a lo largo del siglo XVI se puede hablar más bien de «intenciones y fragmentos renacentistas», más que de ciudades renacentistas. Sin embargo, en aquel trabajo, no estudió el caso de las ciudades hispanoamericanas (p. 89). 
América representaba, en este sentido, la oportunidad de poner en práctica las ideas sobre la ciudad renacentista que se recibieron en España en la época de Carlos $V$, la oportunidad de construir nuevas ciudades de forma ordenada desde un principio, sin herencias ni obligaciones de siglos de historia. Este aspecto fue aprovechado discursivamente por Oviedo en sus panegíricos de ciudades. Con todo, en las ordenanzas de Carlos $\mathrm{V}$, así como en las instrucciones anteriores dadas a los conquistadores, probablemente la preocupación principal -tal y como señala Hardoy - no fuera otra que facilitar «la más equitativa subdivisión en lotes urbanos y quintas suburbanas entre los fundadores, previendo las necesidades de futuros pobladores» ${ }^{13}$.

Es interesante comprobar cómo cuando Gonzalo Fernández de Oviedo escribe sobre Santo Domingo años después, en la Historia, la perspectiva sobre la ciudad había cambiado ligeramente. Oviedo volvió sobre Santo Domingo en el capítulo décimo del libro tercero de su Historia, al hablar de la gobernación del comendador mayor, Nicolás de Ovando. El discurso de la maravilla permanece y Oviedo traza un panegírico siguiendo un esquema similar al que hemos visto en el Sumario. En este sentido, Santo Domingo seguía siendo una ciudad a la que otras poblaciones de España no hacían ventaja, «tan bien edificada que ningún pueblo hay en España, tanto por tanto, mejor labrado generalmente, dejando aparte la insigne e muy noble cibdad de Barcelona» ${ }^{14}$. Por otro lado, las riquezas de la isla Española y las condiciones de la ciudad de Santo Domingo eran tales que «lo que aquí sobra a otras provincias haría muy ricas», dice. De hecho, «si un príncipe no tuviese más señorío de aquesta isla sola, en breve tiempo sería tal que hiciese ventaja a las islas de Secilia e Inglaterra», dos «de las mayores y mejores de los cristianos» ${ }^{15}$. La comparación, "odiosa para algunos de los que escuchan lo que no querrían oír» ${ }^{16}$, no era casual, ya que se inscribía en el discurso de Oviedo sobre la superioridad del Imperio español gracias, precisamente, a sus posesiones americanas ${ }^{17}$.

Siendo así, continúa Oviedo, «podrá decir el inglés» que no se puede admitir lo que digo, al ser Inglaterra una isla rica, fértil, habitada de nobles, reyes y gente belicosa desde antiguo, con 19 obispados, 50 ciudades, entre ellas Londres, «una de las más famosas de la Cristiandad», y otras muchas razones. Lo mismo ocurre con Sicilia. Y todo ello no hace sino reforzar la afırmación de Oviedo, al añadir,

pues desde tantos siglos aquellas islas están pobladas de gente de razón, e con corte de príncipes e reyes tan señalados como en la una y en la otra ha habido, que tanto más se debe estimar nuestras isla, pues siempre ha estado en poder de gente salvaje e bestial, e que su principio se puede contar desde el año de 1492 años, que los primeros cristianos aquí vinieron con el primero almirante, don Cristóbal Colom (que en este de 1547 son 55 años). Y en tan breve tiempo, estar las cosas desta isla en el estado que es dicho hase de tener en mucho, e atribuirse a

13. Hardoy, 1975, p. 316. Ver también Hardoy, 1972.

14. Fernández de Oviedo, Historia, vol. I, p. 77

15. Fernández de Oviedo, Historia, vol. I, p. 78.

16. Fernández de Oviedo, Historia, vol. I, p. 78.

17. Carrillo, 2004. 
solo Dios e a la buena ventura de los Reyes Católicos de España y al invictivísimo emperador don Carlos [...] e a la diligencia e virtud de sus mílites y vasallos caste$\|_{\text {llanos }}{ }^{18}$.

Por tanto, a pesar de la juventud de la ciudad y de que no pueda reivindicar siglos de historia y de grandes hazañas, en tan solo medio siglo son ya muchos los logros de los que se puede dar muestra. Este, como ya he mencionado, es el punto en el que el discurso sobre las ciudades de nueva creación en América se distancia de otras casos en que el panegírico se refiere a ciudades del Viejo Mundo.

Con todo, en la Historia Oviedo matizará el panegírico sin objeciones que hiciera en el Sumario. Como cronista oficial de Indias (desde 1532), Oviedo quiere ser fiel a la verdad y, al dar comienzo a la descripción, cuestiona la decisión del comendador Ovando de cambiar la ubicación de la ciudad: «yo no le pienso loar - dice él- haber pasado aquí la cibdad, ni haberla quitado de la otra costa o ribera deste río, donde primero fue fundada» ${ }^{19}$. El lugar elegido por Ovando se manifestaba como equivocado, en primer lugar, porque al amanecer, al estar al otro lado del río Ozama, el sol hace que las nieblas caigan sobre la población. Y en segundo lugar, por la dificultad de acceder a la fuente de agua más cercana, que está, precisamente, al otro lado del río. Tal vez «esta inadvertencia del comendador mayor» se debiera - dice Oviedo- a que canalizar agua desde otro río cercano (el Haina) no era una tarea difícil de llevar a cabo. Aunque había otra posible explicación para el cambio:

pudo cambiar la mudanza deste pueblo que siempre los gobernadores nuevos quieren enmendar las obras de los pasados, o dar forma cómo se olvide lo que los antecesores en el oficio obraron, para escurecer la fama del que pasó ${ }^{0}$.

Oviedo no lo dice expresamente, pero probablemente el argumento de más peso que evidenciaba la equivocación de Ovando era que el cambio contradecía expresamente lo recogido por la ordenanza de Carlos $\vee$ que, respecto al lugar del asentamiento, decía:

funden en parte donde no estén sujetos a nieblas, haciendo observación de lo que más convenga a la salud y accidentes que se pueden ofrecer; y en caso de edificar a la ribera de algún río, dispongan la población de forma que saliendo el sol dé primero en el pueblo que en el agua ${ }^{21}$.

Pero, más allá del cambio de asentamiento, «todo lo desta vida sana y adolece», se lamentaba Oviedo. Al escribir este pasaje de la Historia la ciudad no estaba tan poblada ni con tanta vecindad como cuando se refirió a ella en el Sumario. Santo Domingo había sido la cabeza desde la que se había impulsado la conquista de

18. Fernández de Oviedo, Historia, vol. I, p. 82.

19. Fernández de Oviedo, Historia, vol. I, p. 76.

20. Fernández de Oviedo, Historia, vol. I, p. 76. Oviedo sabía, no obstante, que el motivo por el que Ovando había trasladado la ubicación de la ciudad de Santo Domingo era el huracán que en 1502 había destruido la ciudad y la mayor parte de la flota en la que había llegado a tierras americanas.

21. Recopilación de leyes de los reinos de las Indias, vol. II, p. 19. 
nuevos territorios y muchos de sus vecinos habían decidido ir en busca de las riquezas que se adivinaban en las noticias sobre el Perú. Santo Domingo no podía competir con los grandes imperios del continente.

Oviedo, desde 1533, era Alcaide de la fortaleza de Santo Domingo, condición desde la que escribe cuando se refiere a dicha ciudad, a la que además representó en diversas ocasiones como procurador ante la administración de justicia ${ }^{22}$. La tristeza por el despoblamiento de la ciudad, así como por la situación en que habían quedado las islas, arrasadas en pocos años, se puede ver claramente en este y otros pasajes de la Historia.

\section{CONCLUSIONES}

Gonzalo Fernández de Oviedo aborda la construcción de un discurso sobre la ciudad americana desde la fórmula retórica del panegírico de la ciudad, frecuente en la época, adaptándolo al hecho de que las poblaciones eran de nueva creación y, por tanto, carecían de siglos de historia. El tópico de los logros históricos y artísticos se modifica en este caso para convertir en una fortaleza lo que podría parecer en principio una debilidad.

Por otro lado, Oviedo modula el discurso al hilo de sus diferentes motivaciones. El discurso se adapta y cambia dependiendo de la mirada desde la que el cronista acomete la labor de escritura. En el Sumario, en un momento de euforia y optimismo con respecto al descubrimiento de América y al proyecto imperial español, Oviedo ensalza las extraordinarias cualidades de Santo Domingo. Por otro lado, hay que tener en cuenta que, en aquel momento, uno de los objetivos de Gonzalo Fernández de Oviedo al escribir el Sumario era convencer a Carlos $\vee$ de la publicación de una gran obra que el cronista ya había comenzado, la Historia general y natural de las Indias, de modo que el discurso de la maravilla se acentúa en aquel libro. Cuando Oviedo regrese sobre la descripción de Santo Domingo años después, en la Historia, lo hará desde una perspectiva matizada con respecto a la conquista de América y lo hará, además, como alcaide de una ciudad en decadencia, precisamente, como él mismo advierte, por las ansias de riqueza de los españoles que viajaban a las Indias Occidentales.

\section{BiBLIOgRAFÍA}

Baraibar, Álvaro, «La Naturaleza en el discurso indiano: la construcción de un espacio de experiencia americano», en Tierras prometidas. De la colonia a la independencia, ed. Bernat Castany et al., Bellaterra, CECE/Universidad Autónoma de Barcelona, 2011, pp. 9-30.

22. Ver al respecto, por ejemplo, el cap. XII del libro V de la Primera Parte, donde relata los sucesos en torno a Alonso López Cerrato y su papel como procurador de Santo Domingo en esta causa (Fernández de Oviedo, Historia, vol. I, pp. 139-141). 
Baraibar, Álvaro, «El concepto de autoridad en la Historia general y natural de las Indias de Gonzalo Fernández de Oviedo», Hispanófila, 171, 2014, pp. 45-57.

Bielza de Ory, Vicente, «De la ciudad ortogonal aragonesa a la cuadricular hispanoamericana como proceso de innovación-difusión, condicionado por la utopía», Scripta Nova. Revista electrónica de Geografía y Ciencias Sociales, 6, 106, 2002. Disponible en: <http://www.ub.edu/geocrit/sn/sn-106.htm> [7/10/2017].

Brewer-Carías, Allan R., La ciudad ordenada, Caracas, Criteria, 2006.

Carrillo, Jesús, Naturaleza e imperio. la representación del mundo natural en la «Historia general y natural de las Indias» de Gonzalo Fernández de Oviedo, Madrid, Doce Calles, 2004.

Curtius, Ernst Robert, Literatura europea y Edad Media latina, México, FCE, 1955.

Fernández de Oviedo, Gonzalo, Historia general y natural de las Indias, ed. Juan Pérez de Tudela Bueso, Madrid, Atlas, 1992, 5 vols.

Fernández de Oviedo, Gonzalo, Sumario de la Natural Historia de las Indias, ed. Álvaro Baraibar, Madrid/Frankfurt, Iberoamericana/Vervuert, 2010.

Goyoaga, Francisco, «La forma española de la ciudad americana», Estudios territoriales, 80, 1989, pp. 95-140.

Hardoy, Jorge E., «Las formas urbanas europeas durante los siglos XV al XVII y su utilización en América Latina», en Urbanización y proceso social en América, III Simposio sobre El proceso de urbanización en América desde sus orígenes hasta nuestros días, Lima, Instituto de Estudios Peruanos, 1972, pp. 157-190.

Hardoy, Jorge E., «La forma de las ciudades coloniales en la América española», en Estudios sobre la ciudad iberoamericana, coord. Francisco de Solano, Madrid, CSIC, 1975, pp. 315-344.

Lleó Cañal, Vicente, Nueva Roma: mitología y humanismo en el Renacimiento sevillano, Sevilla, Diputación Provincial, 1979.

Marías, Fernando, «Las ciudades del siglo XVI y el urbanismo renacentista», en Ciudades del Siglo de Oro. Las vistas españolas de Anton van den Wyngaerde, dir. Richard L. Kagan, Madrid, El Viso, 1986, pp. 84-105.

Nicolini, Alberto, «La ciudad hispanoamericana, medieval, renacentista y americana», Atrio. Revista de Historia del Arte, 10/11, 2005, pp. 27-36.

Pérez de Tudela, Juan, «Estudio preliminar. Vida y escritos de Gonzalo Fernández de Oviedo», en Gonzalo Fernández de Oviedo, Historia general y natural de las Indias, Madrid, Atlas, 1992, vol. 1, pp. VII-CLXXV.

Recopilación de leyes de los reinos de las Indias, Madrid, Consejo de la Hispanidad,1943, 3 vols. 
Solano, Francisco de (dir.), Historia urbana de Iberoamérica, t. 1. La ciudad iberoamericana hasta 1573, Madrid, Consejo Superior de los Colegios de Arquitectos de España, 1987.

Solano, Francisco de, Ciudades hispanoamericanas y pueblos de indios, Madrid, CSIC, 1990.

Solano, Francisco de, Normas y leyes de la ciudad hispaniamericana, 1492-7600, Madrid, CSIC, 1996.

Teglia, Vanina María, «Una corte de caballeros para el Nuevo Mundo: los proyectos [utópicos] de Gonzalo Fernández de Oviedo», Corpus. Archivos virtuales de la alteridad americana, 2, 1, 2012, pp. 1-20. 
